\section{A Randomized Trial of Genotype-Guided Dosing of Acenocoumarol and Phenprocoumon}

\author{
Talitha I. Verhoef, M.Sc., Georgia Ragia, Ph.D., Anthonius de Boer, M.D., Ph.D., \\ Rita Barallon, Ph.D., Genovefa Kolovou, M.D., Ph.D., Vana Kolovou, M.Sc., \\ Stavros Konstantinides, M.D., Ph.D., Saskia Le Cessie, Ph.D., \\ Efstratios Maltezos, M.D., Ph.D., Felix J.M. van der Meer, M.D., Ph.D., \\ William K. Redekop, Ph.D., Mary Remkes, M.D., Frits R. Rosendaal, M.D., Ph.D., \\ Rianne M.F. van Schie, Ph.D., Anna Tavridou, Ph.D., Dimitrios Tziakas, M.D., Ph.D., \\ Mia Wadelius, M.D., Ph.D., Vangelis G. Manolopoulos, Ph.D., \\ and Anke H. Maitland-van der Zee, Pharm.D., Ph.D., for the EU-PACT Group*
}

A B STRACT

BACKGROUND

Observational evidence suggests that the use of a genotype-guided dosing algorithm may increase the effectiveness and safety of acenocoumarol and phenprocoumon therapy.

\section{METHODS}

We conducted two single-blind, randomized trials comparing a genotype-guided dosing algorithm that included clinical variables and genotyping for CYP2C9 and VKORC1 with a dosing algorithm that included only clinical variables, for the initiation of acenocoumarol or phenprocoumon treatment in patients with atrial fibrillation or venous thromboembolism. The primary outcome was the percentage of time in the target range for the international normalized ratio (INR; target range, 2.0 to 3.0) in the 12 -week period after the initiation of therapy. Owing to low enrollment, the two trials were combined for analysis. The primary outcome was assessed in patients who remained in the trial for at least 10 weeks.

\section{RESULTS}

A total of 548 patients were enrolled (273 patients in the genotype-guided group and 275 in the control group). The follow-up was at least 10 weeks for 239 patients in the genotype-guided group and 245 in the control group. The percentage of time in the therapeutic INR range was $61.6 \%$ for patients receiving genotype-guided dosing and $60.2 \%$ for those receiving clinically guided dosing $(\mathrm{P}=0.52)$. There were no significant differences between the two groups for several secondary outcomes. The percentage of time in the therapeutic range during the first 4 weeks after the initiation of treatment in the two groups was $52.8 \%$ and $47.5 \%(\mathrm{P}=0.02)$, respectively. There were no significant differences with respect to the incidence of bleeding or thromboembolic events.

\section{CONCLUSIONS}

Genotype-guided dosing of acenocoumarol or phenprocoumon did not improve the percentage of time in the therapeutic INR range during the 12 weeks after the initiation of therapy. (Funded by the European Commission Seventh Framework Programme and others; EU-PACT ClinicalTrials.gov numbers, NCT01119261 and NCT01119274.)
The authors' affiliations are listed in the Appendix. Address reprint requests to Dr. Maitland-van der Zee at Utrecht University, Faculty of Science, Division of Pharmacoepidemiology and Clinical Pharmacology, P.O. Box 80 082, 3508 TB Utrecht, the Netherlands, or at a.h.maitland@uu.nl; or to Dr. Manolopoulos at the Laboratory of Pharmacology, Medical School, Democritus University of Thrace, 68100 Alexandroupolis, Greece, or at emanolop@med.duth.gr.

*Members of the European Pharmacogenetics of Oral Anticoagulant Therapy (EU-PACT) Group are listed in the Supplementary Appendix, available at NEJM.org.

This article was published on November 19, 2013, at NEJM.org.

DOI: 10.1056/NEJMoal311388

Copyright $\odot 2013$ Massachusetts Medical Society 
OUMARIN ANTICOAGULANT AGENTS such as acenocoumarol, phenprocoumon, and warfarin are frequently used for the prevention of stroke in patients with atrial fibrillation or for the treatment and prevention of venous thromboembolism. ${ }^{1}$ In many countries, warfarin is used most frequently, but in some countries, acenocoumarol or phenprocoumon is prescribed. ${ }^{2}$ Coumarin anticoagulant drugs have a narrow therapeutic window, and there are large interpatient and intrapatient variations in the dose requirement. The anticoagulant effect of these drugs is monitored by means of regular measurement of the international normalized ratio (INR). ${ }^{3}$ A subtherapeutic INR is associated with an increased risk of stroke or thromboembolism, whereas a supratherapeutic INR is associated with an increased risk of bleeding. ${ }^{4}$

Several factors influence the stability of the INR and the required coumarin dose. These factors include age, height, weight, sex, concomitant medication use, and diet, but genetic factors also play an important role. ${ }^{5}$ Polymorphisms in two genes - VKORC1 (encoding the target enzyme of the drug, vitamin $\mathrm{K}$ epoxide reductase complex, subunit 1) and CYP2C9 (encoding the main metabolizing enzyme, cytochrome P-450, family 2, subfamily C, polypeptide 9) - together explain approximately one third of the variation in the dose requirement. ${ }^{6,7}$ Therefore, dosing algorithms that use this genetic information may improve the prediction of the required coumarin dose and thereby increase the effectiveness and safety of the treatment.

The use of an algorithm that does not include genetic information but does include factors such as age, height, and weight may also improve the prediction of the required dose. Therefore, it is important to compare a dosing algorithm that includes genetic information with a dosing algorithm that does not include genetic information. This approach has been investigated in small or nonrandomized clinical trials with warfarin, 8,9 but it has not been studied with acenocoumarol or phenprocoumon. As part of the European Pharmacogenetics of Oral Anticoagulant Therapy (EU-PACT) consortium, we investigated the effectiveness and safety of an algorithm including VKORC1 and CYP2C9 genotypes and clinical factors, as compared with an algorithm including only clinical factors, for the initiation of dosing with acenocoumarol or phenprocoumon. ${ }^{10}$

METHODS

\section{STUDY DESIGN}

The acenocoumarol and phenprocoumon components of the EU-PACT study were originally designed as two separate multicenter, singleblind, randomized, controlled trials. The acenocoumarol trial was conducted in the Netherlands and in Greece, and the phenprocoumon trial was conducted in the Netherlands. The two trials (one with acenocoumarol and the other with phenprocoumon) compared the effect of a genotype-guided dosing algorithm with the effect of a dosing algorithm based solely on clinical factors (control). The design of the two trials is described in detail elsewhere. ${ }^{10}$ Because of low power resulting from low enrollment, the trials were combined for analysis.

The trials were designed by the members of the EU-PACT study group. Data were gathered by all the investigators and coinvestigators (for a full list, see the Supplementary Appendix, available with the full text of this article at NEJM.org) and were analyzed by the first author and a statistician who is an author, who vouch for the accuracy and completeness of the data reported. All the authors vouch for the adherence of the study to the protocols, which are available at NEJM.org. The first draft of the manuscript was written by the first author in close collaboration with the last author, with input from the other authors. The first two authors and the last two authors made the decision to submit the manuscript for publication.

The Leiden Medical Ethics Committee approved the study protocols in the Netherlands, and the Scientific Council and Ethics Committee of the Academic General Hospital of Alexandroupolis and the institutional review board of the Onassis Cardiac Surgery Center approved the study protocol in Greece. An independent data and safety monitoring board periodically reviewed the efficacy and safety data. All medications were purchased. The trials were funded by the European Commission Seventh Framework Programme. LGC (formerly Laboratory of the Government Chemist) provided the point-of-care genotyping assay with funding from the European 
Union. The funder and LGC had no role in the collection and interpretation of the data or in the writing of the manuscript or the decision to submit it for publication.

\section{PATIENTS}

Patients who had received a diagnosis of atrial fibrillation or venous thromboembolism and for whom at least 12 weeks of acenocoumarol or phenprocoumon treatment was planned were asked to participate in the trials. The trials enrolled only patients who had not received coumarin therapy previously. Detailed inclusion and exclusion criteria are provided in the Supplementary Appendix. All the patients provided written informed consent.

\section{RANDOMIZATION AND TREATMENT}

Patients were randomly assigned in a 1:1 ratio to either the genotype-guided group or the control group. Block randomization was performed according to a computer-generated randomization list, with the use of a block size of 10 , and was stratified according to study center and indication (atrial fibrillation or venous thromboembolism). Patients were unaware of the treatment assignment.

During the first 5 to 7 days of treatment (typically 6 days with 1 day of scheduling leeway), patients in the genotype-guided group were treated according to a dosing algorithm that included genotype information, and those in the control group were treated according to a dosing algorithm that included only clinical information. After the first 5 to 7 days, patients were treated on the basis of the INR and in accordance with local clinical practice. Details about the genotyping and the specific dosing algorithms are provided in the Supplementary Appendix. Coumarin therapy was initiated on an outpatient basis in the Netherlands and on an inpatient basis in Greece.

\section{FOLLOW-UP}

The intended follow-up period for all patients was 12 weeks. Anticoagulation status was monitored by means of INR measurement, before the daily dose of the coumarin anticoagulant was administered, on days $1,4,6,8,15,22,57$, and 85 . The measurements planned on days 4 through 85 could be adjusted slightly to coincide with weekdays. Additional INR measurements were carried out if clinically relevant. On the day of INR mea- surement, the patients were also asked whether they had had any possible adverse events.

\section{OUTCOME MEASURES}

The primary outcome in both trials was the percentage of time in the therapeutic INR range (2.0 to 3.0) during the 12 weeks after the initiation of coumarin therapy. In the Netherlands, the usual therapeutic INR range is 2.0 to 3.5 , but patients included in the trial were all treated with a target range of 2.0 to 3.0. The percentage of time in the therapeutic range was calculated with the use of linear interpolation according to the method of Rosendaal et al. ${ }^{11}$

Secondary outcomes included the number of patients with an INR of 4.0 or more, the percentage of time with an INR of 4.0 or more or with an INR of less than 2.0, the time it took to reach a therapeutic INR, the time it took to achieve a stable dose, and the percentage of patients with a stable dose within 12 weeks. Additional secondary outcomes were the number of minor and major bleeding events, the number of thromboembolic events, and the incidences of coumarin sensitivity and resistance. We also analyzed the percentage of time in the therapeutic range during the first 4 weeks, during weeks 5 through 8 , and during weeks 9 through 12 separately. Definitions of the outcomes are provided in the Supplementary Appendix.

\section{STATISTICAL ANALYSIS}

We originally calculated that for each study to have $80 \%$ power to show a $5 \%$ improvement in the time in the therapeutic range with the genotype-guided dosing algorithm over the standard clinical algorithm, with a standard deviation of $26.5 \%$ and at a $5 \%$ significance level, we would need to enroll 442 patients in each group. Assuming a $10 \%$ withdrawal rate after study entry, we planned to include 986 patients in each study.

We performed a revised power calculation after new data became available from a trial conducted by Anderson et al. ${ }^{12}$ We increased the estimate of the expected improvement in the time in the therapeutic range (on the basis of data from Anderson et al.) and used a new estimate of the expected standard deviation (derived from data collected in the EU-PACT trial up to the date of the revised power calculation). To detect a $7 \%$ improvement in the time in the therapeutic 
range, with a standard deviation of $23 \%$, a twosided significance level of $5 \%$, and $80 \%$ power, we estimated that a sample of 200 patients in each group was necessary, assuming a withdrawal rate of $10 \%$. As a consequence of low enrollment, the overall study coordinator and the national coordinators in Greece and the Netherlands ultimately decided, before data unblinding, to conclude the two trials before the revised enrollment goal was reached and to combine the trials for analysis.

Only patients with at least 10 weeks of followup were included in the analyses, with the exception of the time-to-event analyses and the separate analyses for the first 4 weeks and for weeks 5 through 8. To increase the power and reduce the risk of bias, we performed a sensitivity analysis of the primary outcome that included data from patients with a follow-up of at least 2 weeks instead of 10 weeks. Per-protocol analyses were also performed.

Separate analyses were performed for acenocoumarol and phenprocoumon and for Greece and the Netherlands, followed by a pooled analysis of the acenocoumarol and phenprocoumon data. The primary outcome was calculated separately for both dosing-algorithm groups in the study, $95 \%$ confidence intervals were constructed for the difference in the mean time in the therapeutic

\begin{tabular}{|c|c|c|c|c|c|c|}
\hline \multirow[t]{2}{*}{ Characteristic } & \multicolumn{2}{|c|}{ Acenocoumarol } & \multicolumn{2}{|c|}{ Phenprocoumon } & \multicolumn{2}{|c|}{$\begin{array}{l}\text { Combined Acenocoumarol } \\
\text { and Phenprocoumon Data }\end{array}$} \\
\hline & $\begin{array}{c}\text { Genotype-Guided } \\
\text { Group } \\
(\mathrm{N}=190)\end{array}$ & $\begin{array}{l}\text { Control } \\
\text { Group } \\
(\mathrm{N}=191)\end{array}$ & $\begin{array}{c}\text { Genotype-Guided } \\
\text { Group } \\
(\mathrm{N}=83)\end{array}$ & $\begin{array}{l}\text { Control } \\
\text { Group } \\
(\mathrm{N}=84)\end{array}$ & $\begin{array}{c}\text { Genotype-Guided } \\
\text { Group } \\
(\mathrm{N}=273)\end{array}$ & $\begin{array}{l}\text { Control } \\
\text { Group } \\
(\mathrm{N}=275)\end{array}$ \\
\hline Age $-y r$ & $68 \pm 14$ & $68 \pm 13$ & $67 \pm 11$ & $67 \pm 11$ & $68 \pm 13$ & $68 \pm 13$ \\
\hline Male sex - no. (\%) & $121(64)$ & $107(56)$ & $51(61)$ & $47(56)$ & $172(63)$ & $154(56)$ \\
\hline White race - no. (\%)† & $184(97)$ & 189 (99) & $79(95)$ & $81(96)$ & $263(96)$ & $270(98)$ \\
\hline Atrial fibrillation - no. (\%) & $158(83)$ & $158(83)$ & $68(82)$ & $70(83)$ & $226(83)$ & $228(83)$ \\
\hline Height $-\mathrm{cm}$ & $172 \pm 11$ & $171 \pm 11$ & $174 \pm 9$ & $173 \pm 10$ & $172 \pm 10$ & $171 \pm 11$ \\
\hline Weight - kg & $84 \pm 15$ & $82 \pm 18$ & $87 \pm 17$ & $83 \pm 16$ & $85 \pm 16$ & $82 \pm 17$ \\
\hline \multicolumn{7}{|l|}{ CYP2C9 genotype - no. (\%) } \\
\hline Data missing & 0 & $4(2 \%)$ & 0 & $3(4 \%)$ & 0 & $7(3 \%)$ \\
\hline$* 1 * 1$ & $111(58)$ & $107(56)$ & $55(66)$ & $57(68)$ & $166(61)$ & $164(60)$ \\
\hline$* 1 * 2$ & $39(21)$ & $33(17)$ & $14(17)$ & $14(17)$ & $53(19)$ & $47(17)$ \\
\hline$* 1 * 3$ & $29(15)$ & $32(17)$ & $11(13)$ & $7(8)$ & $40(15)$ & $39(14)$ \\
\hline$* 2 * 2$ & $4(2)$ & $11(6)$ & $2(2)$ & $2(2)$ & $6(2)$ & $13(5)$ \\
\hline$* 2 * 3$ & $5(3)$ & $4(2)$ & $1(1)$ & $1(1)$ & $6(2)$ & $5(2)$ \\
\hline$* 3 * 3$ & $2(1)$ & 0 & 0 & 0 & $2(1)$ & 0 \\
\hline $\begin{array}{l}\text { Hardy-Weinberg equilibrium for } \\
\text { CYP2C9 genotype - } \mathrm{P} \text { value }\end{array}$ & 0.37 & 0.002 & 0.66 & 0.77 & 0.89 & 0.002 \\
\hline \multicolumn{7}{|l|}{ VKORC1 genotype - no. (\%) } \\
\hline Data missing & 0 & $4(2)$ & 0 & $3(4)$ & 0 & $7(3)$ \\
\hline GG & $70(37)$ & $55(29)$ & $24(29)$ & $33(39)$ & $94(34)$ & $88(32)$ \\
\hline GA & $84(44)$ & $93(49)$ & $40(48)$ & $33(41)$ & $124(45)$ & $126(46)$ \\
\hline AA & $36(19)$ & $39(20)$ & $19(23)$ & $15(18)$ & $55(20)$ & $54(20)$ \\
\hline $\begin{array}{l}\text { Hardy-Weinberg equilibrium for } \\
\text { VKORC1 genotype }-\mathrm{P} \text { value }\end{array}$ & 0.23 & 0.97 & 0.77 & 0.20 & 0.23 & 0.47 \\
\hline Amiodarone use - no. (\%) & $22(12)$ & $23(12)$ & 0 & 0 & $22(8)$ & $23(8)$ \\
\hline
\end{tabular}

* Plus-minus values are means \pm SD. No significant differences with respect to baseline characteristics were found between the genotypeguided and control groups.

$\uparrow$ Race was self-reported. 
INR range, and a two-sample t-test was carried out to determine whether the difference was significant. For the secondary outcomes, chi-square tests and time-to-event log-rank tests were used. A nominal two-sided $\mathrm{P}$ value of 0.05 was considered to indicate statistical significance.

\section{RESULTS}

\section{PATIENTS}

A total of 1560 patients were assessed for eligibility, and 548 were enrolled in the two trials (381 patients treated with acenocoumarol and 167 treated with phenprocoumon). Of these, 273 patients were assigned to the genotype-guided group and 275 to the control group. Patient enrollment and treatment assignments are shown in Figure S1 in the Supplementary Appendix.

The modified intention-to-treat population included 484 patients, which excluded 64 patients who did not have at least 10 weeks of the intended 12 weeks of follow-up. An additional 140 patients were excluded from the per-protocol analysis for the reasons outlined in Table S1 in the Supplementary Appendix. The baseline characteristics of the patients in the two dosing-algorithm groups were similar (Table 1, and Table S2 in the Supplementary Appendix).

\section{PRIMARY OUTCOME}

Among patients treated with acenocoumarol, the percentage of time in the therapeutic INR range during the 12 -week study period was $62.3 \%$ in the genotype-guided group and $61.4 \%$ in the control group (difference [genotype-guided group minus control group], 0.9 percentage points; $95 \%$ confidence interval [CI], -4.3 to $6.1 ; \mathrm{P}=0.74$ ); among patients treated with phenprocoumon, the corresponding percentages of time were $60.1 \%$ and $57.6 \%$ (difference, 2.5 percentage points; $95 \% \mathrm{CI}$, -4.5 to $9.4 ; \mathrm{P}=0.49$ ) (Table 2). When all the data were pooled, the time in the therapeutic range was $61.6 \%$ in the genotype-guided group and $60.2 \%$ in the control group (difference, 1.4 percentage points; $95 \% \mathrm{CI},-2.8$ to $5.5 ; \mathrm{P}=0.52$ ). The sensitivity analysis that included data from all patients with a follow-up of at least 2 weeks yielded similar results (Table S3 in the Supplementary Appendix). The mean INR over time is shown for the two dosing-algorithm groups in Figure $1 \mathrm{~A}$, and the time in the therapeutic range is shown for these groups in Figure 1B.

\section{SECONDARY OUTCOMES}

Most of the secondary outcomes did not differ significantly between the two dosing-algorithm groups (Table 3). The time in the therapeutic range during the first 4 weeks after the initiation of treatment was higher among patients in the genotype-guided group, and this difference was significant in the combined analysis of acenocoumarol and phenprocoumon $(52.8 \%$ vs. $47.5 \%$; $\mathrm{P}=0.02$ ). Figure 2 shows the time it took to reach a therapeutic INR and the time it took to achieve a stable dose in the two dosing-algorithm groups. Secondary outcomes according to country are

\footnotetext{
Table 2. Percentage of Time in the Therapeutic Range for the International Normalized Ratio (INR) during 12 Weeks after the Initiation of Treatment.*

\begin{tabular}{|c|c|c|c|c|}
\hline Coumarin Group & $\begin{array}{l}\text { Genotype-Guided } \\
\text { Group } \\
(\mathrm{N}=\mathbf{2 3 9}) \\
\text { percent of time in the }\end{array}$ & $\begin{array}{l}\text { Control } \\
\text { Group } \\
(\mathrm{N}=245) \\
\text { utic INR range }\end{array}$ & $\begin{array}{c}\text { Difference } \\
(95 \% \mathrm{Cl}) \grave{\dagger}\end{array}$ & P Value \\
\hline \multicolumn{5}{|l|}{ Acenocoumarol } \\
\hline Greece & $62.6 \pm 26.7$ & $64.1 \pm 23.8$ & $-1.5(-9.3$ to 6.2$)$ & 0.70 \\
\hline The Netherlands & $62.0 \pm 21.9$ & $58.6 \pm 22.3$ & $3.4(-3.5$ to 10.3$)$ & 0.33 \\
\hline Combined study sites & $62.3 \pm 24.4$ & $61.4 \pm 23.2$ & $0.9(-4.3$ to 6.1$)$ & 0.74 \\
\hline Phenprocoumon & $60.1 \pm 21.1$ & $57.6 \pm 23.3$ & $2.5(-4.5$ to 9.4$)$ & 0.49 \\
\hline $\begin{array}{c}\text { Combined acenocoumarol and } \\
\text { phenprocoumon data }\end{array}$ & $61.6 \pm 23.3$ & $60.2 \pm 23.2$ & $1.4(-2.8$ to 5.5$)$ & 0.52 \\
\hline
\end{tabular}

* Plus-minus values are means \pm SD. The phenprocoumon trial was conducted only in the Netherlands. $\mathrm{Cl}$ denotes confidence interval.

$\uparrow$ The between-group difference was calculated as the genotype-guided group minus the control group.
} 

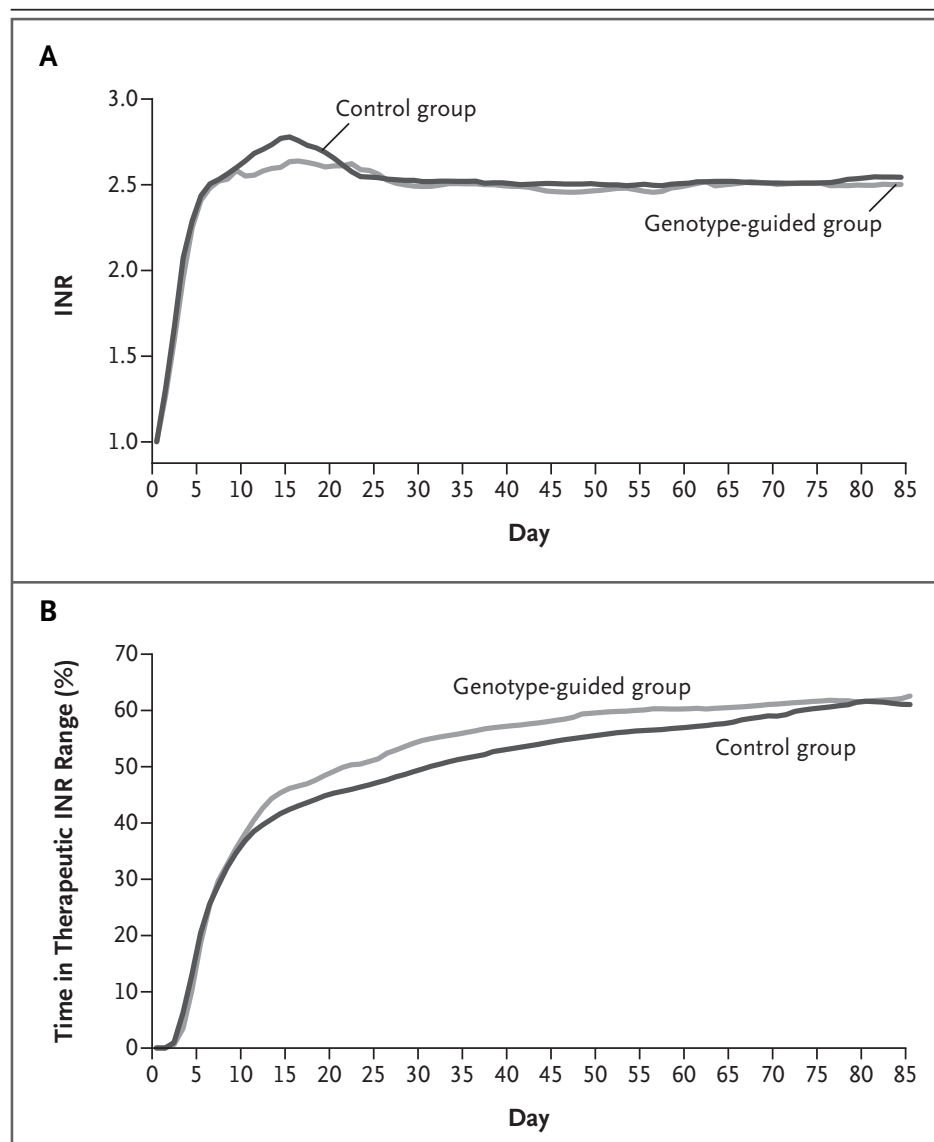

Figure 1. Mean International Normalized Ratio (INR) and Time in the Therapeutic Range.

Panel $A$ shows the difference in the mean INR between the genotype-guided group and the control group, and Panel B the percentage of time within the therapeutic INR range during the 12-week follow-up period. Data were included for all patients with at least 2 weeks of follow-up. shown in Table S4 in the Supplementary Appendix. A per-protocol analysis of the data yielded similar results (Tables S5 through S8 in the Supplementary Appendix).

The incidence of adverse events did not differ significantly between the two dosing-algorithm groups (Table 3, and Table S9 in the Supplementary Appendix). There was only one major bleeding episode, which occurred in the control group. Thromboembolic events occurred in five patients in the genotype-guided group and in four in the control group.

\section{DISCUSSION}

In the EU-PACT trials, we investigated the use of a dosing algorithm that included both pharma- cogenetic and clinical factors, as compared with an algorithm that included only clinical factors, for the initiation of treatment with acenocoumarol or phenprocoumon. There was no significant difference between the two groups in the primary outcome of time in the therapeutic INR range during the first 12 weeks of treatment. There were also no significant differences in most of the secondary outcomes, including the percentage of patients with an INR of 4.0 or more, the percentage of time with an INR of 4.0 or more or an INR of less than 2.0, the median time it took to reach a therapeutic INR, and the percentage of patients with a stable dose within 12 weeks.

We found a significant between-group difference in the time in the therapeutic range during the first 4 weeks of treatment. This observation must be interpreted cautiously. The division of the 12-week study into three 4-week intervals was not prespecified in the trial protocol, and it is only one of several secondary outcome measures. Because the P values in our study were not corrected for multiple testing, it is possible that the significant difference detected in the first 4 weeks is a chance finding.

However, it is biologically plausible that the benefit of pharmacogenetically guided dosing, if there is one, would be most likely to occur during the initiation of treatment. The trial algorithms were used to determine drug doses only during the first 5 to 7 days of treatment. Thereafter, in both groups, adjustments were based on the INR. The fact that we found an effect only in the first month of treatment is consistent with previous observational studies in which we found differences in over- and under-anticoagulation (i.e., supratherapeutic and subtherapeutic INRs) between the genotypes only in the first month. ${ }^{13,14}$

Anderson et al. found a significant difference in the percentage of time in the therapeutic INR range in the first month as well as in the first 3 months of warfarin treatment. ${ }^{12}$ Their study was a nonrandomized comparison with a parallel control group in which standard anticoagulation therapy was provided without a dosing algorithm. In our study, the patients in the control group received a dose that was based on a clinical algorithm, which was also expected to improve the time within the therapeutic range. In a smaller, randomized, controlled trial conducted by Burmester et al., no significant difference in the time in the therapeutic range during the first 14 days was shown between pharmaco- 


\begin{tabular}{|c|c|c|c|c|c|c|c|c|c|}
\hline \multirow[t]{2}{*}{ Outcome } & \multicolumn{3}{|c|}{ Acenocoumarol } & \multicolumn{3}{|c|}{ Phenprocoumon } & \multicolumn{3}{|c|}{$\begin{array}{l}\text { Combined Acenocoumarol } \\
\text { and Phenprocoumon Data }\end{array}$} \\
\hline & $\begin{array}{l}\text { Genotype- } \\
\text { Guided } \\
\text { Group } \\
(\mathrm{N}=160)\end{array}$ & $\begin{array}{l}\text { Control } \\
\text { Group } \\
(\mathrm{N}=165)\end{array}$ & P Value & $\begin{array}{l}\text { Genotype- } \\
\text { Guided } \\
\text { Group } \\
(\mathrm{N}=79)\end{array}$ & $\begin{array}{l}\text { Control } \\
\text { Group } \\
(\mathrm{N}=80)\end{array}$ & P Value & $\begin{array}{l}\text { Genotype- } \\
\text { Guided } \\
\text { Group } \\
(\mathrm{N}=239)\end{array}$ & $\begin{array}{l}\text { Control } \\
\text { Group } \\
(\mathrm{N}=245)\end{array}$ & P Value \\
\hline \multicolumn{10}{|l|}{ Secondary outcomes } \\
\hline \multicolumn{10}{|l|}{$\begin{array}{l}\text { Percentage of time in } \\
\text { therapeutic INR } \\
\text { range }\end{array}$} \\
\hline Wk $1-4$ & 54.5 & 50.4 & 0.15 & 49.0 & 41.2 & 0.05 & 52.8 & 47.5 & 0.02 \\
\hline Wk 5-8 & 66.0 & 62.8 & 0.40 & 61.6 & 60.1 & 0.92 & 64.6 & 62.2 & 0.44 \\
\hline Wk 9-12 & 66.0 & 70.9 & 0.21 & 69.5 & 69.8 & 0.95 & 67.1 & 70.6 & 0.28 \\
\hline Patients with INR $\geq 4.0(\%)$ & 33.1 & 33.3 & 0.97 & 26.6 & 32.5 & 0.41 & 31.0 & 33.1 & 0.62 \\
\hline $\begin{array}{l}\text { Percentage of time with } \\
\text { INR } \geq 4.0\end{array}$ & 2.8 & 2.7 & 0.90 & 2.0 & 3.7 & 0.09 & 2.5 & 3.0 & 0.44 \\
\hline $\begin{array}{l}\text { Percentage of time with } \\
\text { INR }<2.0\end{array}$ & 22.4 & 19.8 & 0.26 & 16.8 & 18.2 & 0.60 & 20.5 & 19.3 & 0.49 \\
\hline \multicolumn{10}{|l|}{$\begin{array}{l}\text { Time to reach therapeutic } \\
\text { INR (days) }\end{array}$} \\
\hline Median & 22 & 22 & 0.76 & 22 & 23 & 0.07 & 22 & 22 & 0.53 \\
\hline $95 \% \mathrm{Cl}$ & $19-25$ & $18-26$ & & $16-28$ & $17-29$ & & $19-25$ & $19-25$ & \\
\hline $\begin{array}{l}\text { Patients with stable dose } \\
\text { within } 12 \mathrm{wk}(\%)^{* *}\end{array}$ & 43.8 & 49.1 & 0.33 & 62.0 & 61.2 & 0.92 & 49.8 & 53.1 & 0.47 \\
\hline $\begin{array}{r}\text { Patients with coumarin } \\
\text { sensitivity }(\%) \dagger\end{array}$ & 2.9 & 5.2 & 0.39 & 5.0 & 8.9 & 0.40 & 3.7 & 6.4 & 0.25 \\
\hline $\begin{array}{r}\text { Patients with coumarin } \\
\text { resistance }(\%)\end{array}$ & 0 & 0 & - & 0 & 0 & - & 0 & 0 & - \\
\hline $\begin{array}{l}\text { Mean no. of INR } \\
\text { measurements }\end{array}$ & 10.6 & 10.7 & 0.65 & 12.5 & 12.6 & 0.86 & 11.2 & 11.3 & 0.68 \\
\hline $\begin{array}{l}\text { Mean absolute difference } \\
\text { between calculated } \\
\text { and achieved stable } \\
\text { doses - mg/day } \mathbb{}\end{array}$ & 0.5 & 0.6 & 0.06 & 0.4 & 0.6 & 0.15 & 22 & 31 & 0.04 \\
\hline \multicolumn{10}{|l|}{ Safety outcomes } \\
\hline $\begin{array}{l}\text { No. of adverse events per } \\
\text { person-mo }\end{array}$ & 1.29 & 0.97 & 0.18 & 1.22 & 1.05 & 0.27 & 1.27 & 1.00 & 0.11 \\
\hline $\begin{array}{l}\text { No. of serious adverse } \\
\text { events per } \\
\text { person-mo }\end{array}$ & 0.07 & 0.06 & 0.78 & 0.13 & 0.02 & 0.16 & 0.09 & 0.05 & 0.25 \\
\hline $\begin{array}{l}\text { No. of bleeding events per } \\
\text { person-mo }\end{array}$ & 0.39 & 0.39 & 0.89 & 0.34 & 0.38 & 0.57 & 0.38 & 0.38 & 0.94 \\
\hline $\begin{array}{l}\text { No. of thromboembolic } \\
\text { events per } \\
\text { person-mo }\end{array}$ & 0.02 & 0.02 & 0.80 & 0.01 & 0.00 & 0.18 & 0.02 & 0.01 & 0.62 \\
\hline
\end{tabular}

* Too few patients in each group had a stable dose by the end of 12 weeks to allow for the calculation of the median time to a stable dose. $\uparrow$ Coumarin sensitivity was documented when the dose that was needed to achieve a stable dose in the therapeutic range was $1.0 \mathrm{mg}$ or less for acenocoumarol or $1.5 \mathrm{mg}$ or less for phenprocoumon.

+ Coumarin resistance was documented when the dose that was needed to achieve a stable dose in the therapeutic range was $8 \mathrm{mg}$ or more for acenocoumarol or $6 \mathrm{mg}$ or more for phenprocoumon.

$\int$ The calculated dose was determined by means of the dosing algorithm, and the achieved stable dose was the stable dose achieved during the trial. The difference was considered to be absolute because the value does not indicate whether the change was an increase or decrease. In the combined coumarin groups, the difference was calculated as a percentage of the achieved stable dose. 


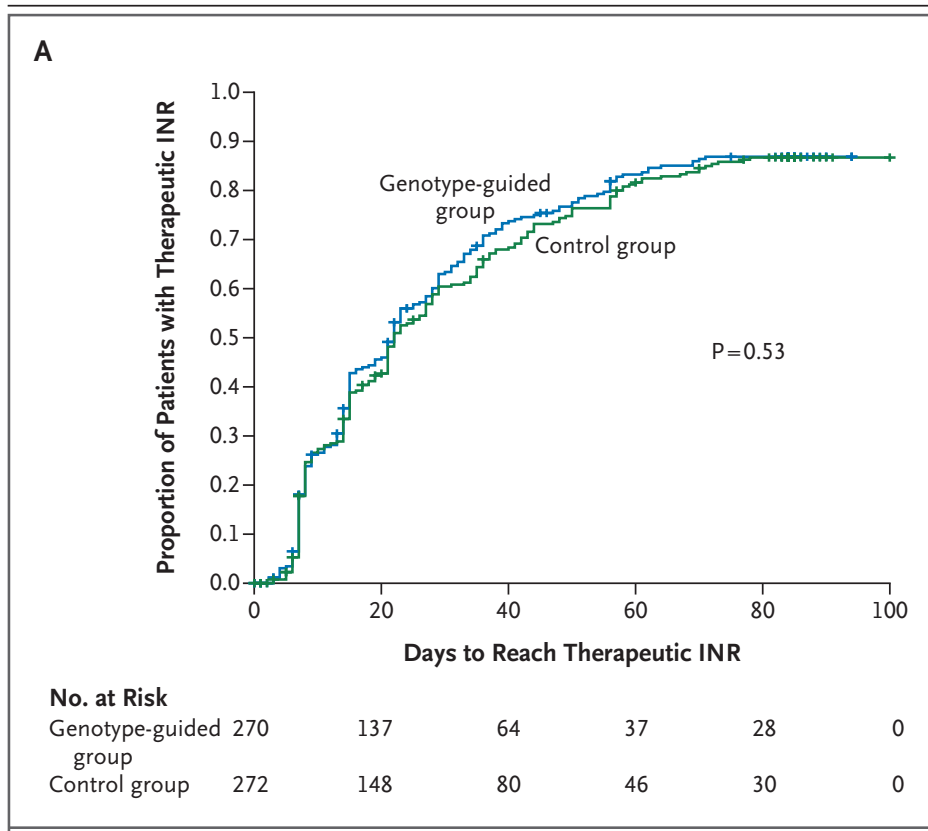

B

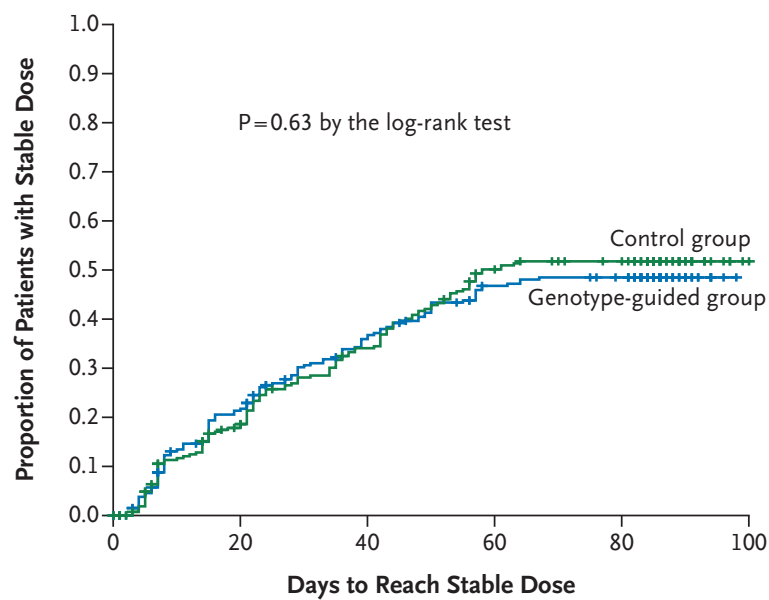

No. at Risk

$\begin{array}{llllll}\begin{array}{l}\text { Genotype-guided } \\ \text { group }\end{array} & 199 & 156 & 124 & 117 & 0 \\ \begin{array}{l}\text { Control group } \\ \text { Contr }\end{array} & 270 & 165 & 122 & 112 & 0\end{array}$

Figure 2. Kaplan-Meier Estimates of the Time to Reach a Therapeutic INR and the Time to Reach a Stable Dose.

Vertical lines indicate the censoring of data due to the occurrence of an event or loss to follow-up. at least 7 days) than we did, and therefore the time it took to reach a stable dose was longer in our study than in the study by Wang et al.

One important difference between all these previous studies and the current one is that the previous studies all evaluated pharmacogenetically guided dosing of warfarin rather than acenocoumarol or phenprocoumon. The CYP2C9 enzyme has much less influence on the pharmacokinetics of phenprocoumon than on the pharmacokinetics of warfarin. ${ }^{16}$ Thus, the effect on the determination of the appropriate dose and dose stability during therapy may be smaller with phenprocoumon than with warfarin, and the effect of the pharmacogenetically guided dosing on the time spent in the therapeutic INR range would also be expected to be less.

One limitation of our trial is the fact that the number of patients included was lower than the number required according to our power calculation. We were able to meet the requirements of our revised sample-size calculation only by pooling the data from the acenocoumarol and phenprocoumon groups. Another limitation was the high number of protocol violations, including incorrectly calculated doses, doses not prescribed according to the protocol, and missing data for dose calculations. However, these issues would also arise if genotyping were implemented in clinical practice.

The percentage of time spent in, below, and above the target INR range is a surrogate outcome used to investigate the quality of anticoagulation. For clinical practice, it is important to determine whether clinical outcomes such as bleeding and thromboembolic events are decreased when genotyping is used. Our study was not powered to detect clinically relevant differences with respect to these events. However, the risks of bleeding and thromboembolic events are lowest when the INR is within the target range. ${ }^{17}$ It is therefore plausible that an intervention that increases the percentage of time in the target range will be associated with a decreased risk of adverse events.

In conclusion, we investigated the use of a dosing algorithm that included both pharmacogenetic and clinical factors, as compared with an algorithm that included only clinical factors, for the initiation of treatment with acenocoumarol or phenprocoumon. There was no significant difference between the two dosing-algorithm groups in the primary outcome of time in the 


\section{therapeutic INR range during the first 12 weeks of treatment.}

Supported by a grant from the European Commission Seventh Framework Programme (HEALTH F2 2009 223062) and by funding from GlaxoSmithKline (to Dr. Maitland-van der Zee) and the Swedish Research Council (Medicine), the Swedish Heart-Lung
Foundation, and Clinical Research Support at Uppsala University (to Dr. Wadelius).

Disclosure forms provided by the authors are available with the full text of this article at NEJM.org.

We thank all the patients who participated in this trial and all the staff at the anticoagulant clinics and hospitals where recruiting was conducted.

APPENDIX

The authors' affiliations are as follows: the Utrecht Institute for Pharmaceutical Sciences, Division of Pharmacoepidemiology and Clinical Pharmacology, Utrecht University, Utrecht (T.I.V., A.B., R.M.F.S., A.H.M.Z.), the Departments of Medical Statistics and Bioinformatics (S.L.C.), Clinical Epidemiology (S.L.C., F.R.R.), and Thrombosis and Hemostasis (F.J.M.M., F.R.R.), Leiden University Medical Center, Leiden, the Institute for Medical Technology Assessment, Erasmus University, Rotterdam (W.K.R.), and Atal-Medical Diagnostics Center, Amsterdam (M.R.) - all in the Netherlands; the Laboratory of Pharmacology (G.R., A.T., V.G.M.) and University Cardiology Department (S.K., D.T.), Medical School, and the Second Department of Internal Medicine (E.M.), Democritus University of Thrace, and the Clinical Pharmacology Unit, Academic General Hospital of Alexandroupolis (A.T., V.G.M.), Alexandroupolis, and the First Cardiology Department, Onassis Cardiac Surgery Center, Athens (G.K., V.K.) — all in Greece; LGC, Teddington, Middlesex, United Kingdom (R.B.); and the Department of Medical Sciences, Clinical Pharmacology, Uppsala University Hospital, Uppsala, Sweden (M.W.).

\section{REFERENCES}

1. Hirsh J, Dalen J, Anderson DR, et al. Oral anticoagulants: mechanism of action, clinical effectiveness, and optimal therapeutic range. Chest 2001;119:Suppl: 8S-21S.

2. Pengo V, Pegoraro C, Cucchini U, Iliceto S. Worldwide management of ora anticoagulant therapy: the ISAM study. J Thromb Thrombolysis 2006;21:73-7.

3. Ansell J, Hirsh J, Hylek E, Jacobson A, Crowther M, Palareti G. Pharmacology and management of the vitamin $\mathrm{K}$ antagonists: American College of Chest Physicians Evidence-Based Clinical Practice Guidelines (8th Edition). Chest 2008;133:Suppl:160S198 S.

4. Merli GJ, Tzanis G. Warfarin: what are the clinical implications of an out-of-rangetherapeutic international normalized ratio? J Thromb Thrombolysis 2009;27:293-9.

5. Schalekamp T, de Boer A. Pharmacogenetics of oral anticoagulant therapy. Curr Pharm Des 2010;16:187-203.

6. Wadelius M, Chen LY, Lindh JD, et al. The largest prospective warfarin-treated cohort supports genetic forecasting. Blood 2009;113:784-92

7. Bodin L, Verstuyft C, Tregouet DA, et al. Cytochrome P450 2C9 (CYP2C9) and vita- min K epoxide reductase (VKORC1) genotypes as determinants of acenocoumarol sensitivity. Blood 2005;106:135-40.

8. Lenzini PA, Grice GR, Milligan PE, et al. Laboratory and clinical outcomes of pharmacogenetic vs. clinical protocols for warfarin initiation in orthopedic patients. J Thromb Haemost 2008;6:1655-62. 9. Burmester JK, Berg RL, Yale SH, et al. A randomized controlled trial of genotypebased Coumadin initiation. Genet Med 2011;13:509-18.

10. van Schie RM, Wadelius MI, Kamali F, et al. Genotype-guided dosing of coumarin derivatives: the European Pharmacogenetics of Anticoagulant Therapy (EU-PACT) trial design. Pharmacogenomics 2009;10:168795.

11. Rosendaal FR, Cannegieter SC, van der Meer FJ, Briët E. A method to determine the optimal intensity of oral anticoagulant therapy. Thromb Haemost 1993; 69:236-9.

12. Anderson JL, Horne BD, Stevens SM, et al. A randomized and clinical effectiveness trial comparing two pharmacogenetic algorithms and standard care for individualizing warfarin dosing (CoumaGen-II). Circulation 2012;125:1997-2005.
13. Verhoef TI, Redekop WK, Hegazy H, de Boer A, Maitland-van der Zee AH. Longterm anticoagulant effects of CYP2C9 and VKORC1 genotypes in phenprocoumon users. J Thromb Haemost 2012;10:2610-2. 14. Verhoef TI, Redekop WK, Buikema $\mathrm{MM}$, et al. Long-term anticoagulant effects of the CYP2C9 and VKORC1 genotypes in acenocoumarol users. J Thromb Haemost 2012;10:606-14.

15. Wang M, Lang X, Cui S, et al. Clinical application of pharmacogenetic-based warfarin-dosing algorithm in patients of Han nationality after rheumatic valve replacement: a randomized and controlled trial. Int J Med Sci 2012;9:472-9.

16. Kirchheiner J, Ufer $M$, Walter EC, et al. Effects of CYP2C9 polymorphisms on the pharmacokinetics of $\mathrm{R}$ - and S-phenprocoumon in healthy volunteers. Pharmacogenetics 2004;14:19-26.

17. Oake N, Jennings A, Forster AJ, Fergusson D, Doucette S, van Walraven C. Anticoagulation intensity and outcomes among patients prescribed oral anticoagulant therapy: a systematic review and meta-analysis. CMAJ 2008;179:235-44.

Copyright (c) 2013 Massachusetts Medical Society. 